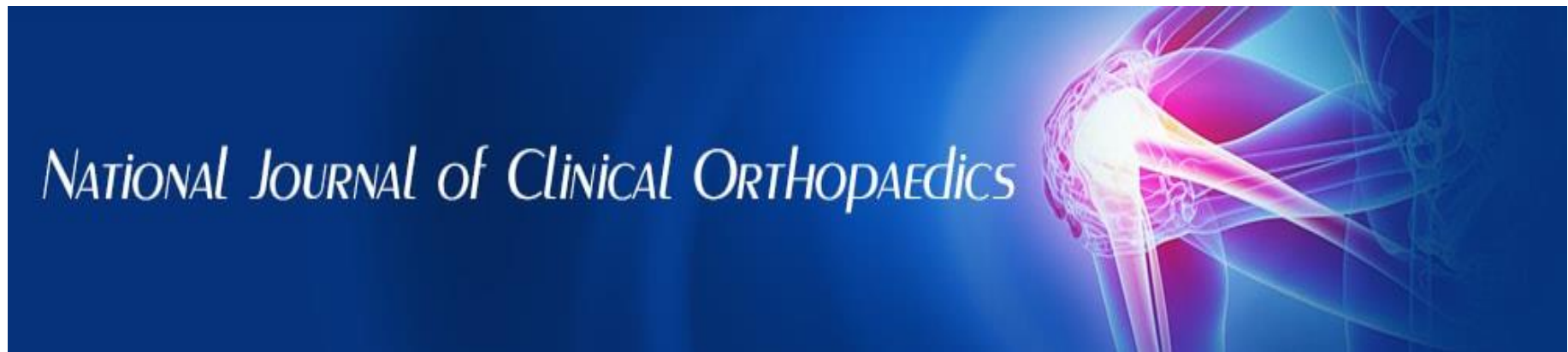

ISSN (P): 2521-3466

ISSN (E): 2521-3474

(C) Clinical Orthopaedics www.orthoresearchjournal.com 2021; 5(3): 112-114

Received: 28-05-2021

Accepted: 30-06-2021

\section{Vinod Kumar Soni}

Orthopaedics Consultant,

Department of Orthopaedics,

Medi-Square Hospital Joint

Replacement Centre, Indore,

Madhya Pradesh, India

\section{Dr. Ritesh Yadav}

Assistant Professor, Department of Orthopaedics, Index Medical College Hospital \& Research

Centre, Indore, Madhya Pradesh, India
Corresponding Author: Dr. Ritesh Yadav

Assistant Professor, Department of Orthopaedics, Index Medical College Hospital \& Research Centre, Indore, Madhya Pradesh, India

\section{To Study The Incidence of missed Distal Radio-Ulnar Joint (Druj) Injuries, Its' Early Diagnosis by Dynamic C.T. Scan and Management by Modified Kapanji Method}

\author{
Vinod Kumar Soni and Dr. Ritesh Yadav
}

DOI: $\underline{\text { https://doi.org/10.33545/orthor.2021.v5.i3b.303 }}$

\section{Abstract}

Background and Method: All the patients coming to the Department of Orthopaedics of Index Medical College Hospital \& Research Centre, Indore, with an aim to Study The Incidence of missed Distal RadioUlnar Joint (Druj) Injuries, Its' Early Diagnosis by Dynamic C.T. Scan and Management by Modified Kapanji Method and diagnosed with distal radio-ulnar joint injuries. All the trauma cases were received in the casualty and primary treatment with detailed examination and required imaging studies were done. The x-ray included antero-posterior and posterio-anterior views with dynamic CT scan and CT scan for head injury patient was donr through all investigation operative procedure were planned. The required consent was taken by the patient beforehand.

Result: DRUJ injuries are more prevalent among young males than females. In age group 16 to 30 female $(45 \%)$ is higher than male $(38.8 \%)$. DRUJ injuries was seen more in left (55\%) than right (45\%) hand. Fall on out stretched hand $(58 \%)$ is the major mechanism of DRUJ injuries followed by trivial trauma in $42 \%$. DRUJ injury was missed in $18.33 \%$, chronic in $20 \%$, acute in $38.33 \%$ and sub-acute in $23.33 \%$.

Conclusion: Present study conclude that DRUJ injuries are more prevalent among young males than females. DRUJ injuries was seen more in left $(55 \%)$ than right $(45 \%)$ hand with fall on out stretched hand is the major mechanism. Physical examination is effective in diagnosis; radiological examination suggested for further investigations. Positive symptoms of DRUJ injuries were in $100 \%$, physical examination was positive in $85 \%$ and negative in $15 \%$. Positive CT findings in $66.67 \%$ and negative in $33.33 \%$. X-ray findings were positive in $71.67 \%$ and negative in $28.33 \%$.

Keywords: incidence, DRUJ, wrist \& joint injuries

\section{Introduction}

The distal radio ulnar joint (DRUJ) is part of forearm articulation that comprises proximal radioulnar joint (PRUJ), forearm bones and interosseous membrane (IOM) allowing the pronosupination. DRUJ functionally and anatomically is included with the ulnocarpal articulation of wrist. The DRUJ has developed from the original pectoral fin of early fish to the bipedal primate wrist to its current form in human wrist. From the syndesmotic DRUJ of brachiating primates with restricted forearm rotation, three key variations happened i.e. development of separate DRUJ, recession of the distal ulna from the ulnar carpus and the development of an ulnocarpal meniscus. (Louis DS et al., 1998) ${ }^{[1]}$.

Fracture of the distal radius is the most common type of fracture in the upper extremity. Because the radius plays a fundamental role in the stability of the wrist joint, preservation of ligamentous function of the wrist and the biomechanics of radio-carpal and radio-ulnar joints, anatomical reduction and correction of articular surface incongruity decreases the potential of degeneration and accelerates post-injury rehabilitation ${ }^{[2]}$.

Distal radius fracture is accompanied by several complications. DRUJ instability, the most disabling complication. The prevalence of DRUJ instability is reported to be $10-19 \%$ after distal radius fracture. Both acute injuries and biomechanical changes related to chronic injuries result in pain and decrease in radio-carpal and radio-ulnar range of motion. (W.B. Geissler, et al. 1996) ${ }^{[3]}$. 
The DRUJ preserve the stability with the help of articular surface congruity and with normal function of triangular fibrocartilage complex (TFCC). The ulnar head articulates with the sigmoid notch of the distal radius and the congruency between the bones provides some stability to the DRUJ, nevertheless this articulation is not deep and depend on soft tissuestabilizers to maintain the joint integrity. TFCC is the most essential soft tissue stabilizer of the DRUJ. The dorsal TFCC is important in stabilizing the DRUJ during pronation whi99le the volar TFCC is important in DRUJ stabilization during supination.

This indispensable stabilizer is commonly injured in distal radius fractures and leads to DRUJ instability. The incidence of TFCC injury in distal radius fracture was shown to be 30 70\%.14 Unrecognized DRUJ injuries cause motion restriction, joint surface incongruity, subluxation of the ulnar head and decreased grip strength. In addition, the DRUJ plays a critical role in normal forearm rotation and early treatment of acute injury provides better results than surgical management of chronic instability. Since the TFCC originates from the base of the ulnar styloid, the fractures involving the proximal half of the ulnar styloid result in DRUJ instability. (M.M. May, et al. 2002) [4].

\section{Material and Method}

All the patients coming to the Department of Orthopaedics of Index Medical College Hospital \& Research Centre, Indore, during the study period from Nov 2017 to 2019 Oct and diagnosed with distal radio-ulnar joint injuries.

The patient's clinical history and examination findings were recorded prospectively in a case record form. Then radiological investigations like X-rays and CT scan were advised.

Opinions of operating consultant surgeon were taken in two separate proformas regarding their findings, diagnosis and plan of management. First opinion was taken on the basis of the Xray alone and second opinion was taken after showing the CT scans. Any change in the plan of management was noted.

All the trauma cases were received in the casualty and primary treatment with detailed examination and required imaging studies were done. The $\mathrm{x}$-ray included antero-posterior and posterio-anterior views with dynamic CT scan and CT scan for head injury patient was donr through all investigation operative procedure were planned. The required consent was taken by the patient beforehand.

\section{Inclusion criteria}

- All candidates having acute, chronic wrist injury.

- All neglected and missed cases of DRUJ injuries.

\section{Exclusion criteria}

-Systemic disease (SLE, Rheumatoid arthritis, osteoarthritis -Un-consenting patient.

\section{Results}

Table 1: Age-Sex distribution of DRUJ injuries

\begin{tabular}{|c|c|c|c|c|c|}
\hline \multirow{2}{*}{ Age } & \multicolumn{2}{|c|}{ Male } & \multicolumn{2}{c|}{ Female } & \multirow{2}{*}{ Total } \\
\cline { 2 - 5 } & Count & \% & Count & \% & \\
\hline 7 to 15 & 9 & 18.37 & 0 & 0.00 & 9 \\
\hline 16 to 30 & 19 & 38.78 & 5 & 45.45 & 24 \\
\hline 31 to 45 & 8 & 16.33 & 3 & 27.27 & 11 \\
\hline 45 to 58 & 13 & 26.53 & 3 & 27.27 & 16 \\
\hline Total & 49 & 81.67 & 11 & 18.33 & 60 \\
\hline
\end{tabular}

DRUJ injuries are more prevalent among young males than females. In age group 16 to 30 female $(45 \%)$ is higher than male $(38.8 \%)$.

Table 2: Site of DRUJ injuries distribution.

\begin{tabular}{|c|c|c|c|c|c|}
\hline \multirow{2}{*}{ Site of Injury } & \multicolumn{2}{|c|}{ Male } & \multicolumn{2}{c|}{ Female } & \multirow{2}{*}{ Total } \\
\cline { 2 - 5 } & Count & \% & Count & \% & \\
\hline Left & 27 & 27.55 & 6 & 27.27 & $33(55 \%)$ \\
\hline Right & 22 & 22.45 & 5 & 22.73 & $27(45 \%)$ \\
\hline Total & 49 & 81.67 & 11 & 18.33 & 60 \\
\hline
\end{tabular}

DRUJ injuries was seen more in left $(55 \%)$ than right $(45 \%)$ hand.

Table 3: Mechanism of DRUJ injuries distribution

\begin{tabular}{|c|c|c|c|c|c|c|}
\hline \multirow{2}{*}{ Site of injury } & \multirow{2}{*}{ Mechanism of Injury } & \multicolumn{2}{|c|}{ Male } & \multicolumn{2}{|c|}{ Female } & \multirow{2}{*}{ Total } \\
\cline { 3 - 6 } & & Count & $\mathbf{\%}$ & Count & $\mathbf{\%}$ & \\
\hline \multirow{2}{*}{ Right } & Trival trauma & 11 & 22.45 & 4 & 36.36 & $15(25 \%)$ \\
\cline { 2 - 6 } & Fall on out stretched hand & 11 & 22.45 & 1 & 18.33 & $12(20 \%)$ \\
\hline \multirow{2}{*}{ Left } & Trival trauma & 9 & 18.37 & 1 & 9.09 & $10(17 \%)$ \\
\cline { 2 - 6 } & Fall on out stretched hand & 18 & 36.73 & 5 & 45.45 & $23(38 \%)$ \\
\hline \multicolumn{2}{|r}{} & 49 & 81.67 & 11 & 18.33 & 60 \\
\hline
\end{tabular}

Fall on out stretched hand $(58 \%)$ is the major mechanism of DRUJ injuries followed by trivial trauma in $42 \%$.

Table 4: Incidence of missed DRUJ injuries.

\begin{tabular}{|c|c|c|}
\hline Injury & Count & \% \\
\hline Missed & 11 & 18.33 \\
\hline Chronic & 12 & 20.00 \\
\hline Acute & 23 & 38.33 \\
\hline Sub-acute & 14 & 23.33 \\
\hline Total & 60 & 100 \\
\hline
\end{tabular}

DRUJ injury was missed in $18.33 \%$, chronic in $20 \%$, acute in $38.33 \%$ and sub-acute in $23.33 \%$.

\section{Discussion}

In present study DRUJ injuries were more prevalent among young males than females. In age group 16 to 30 female (45\%) is higher than male (83.8\%).Similarly in the study of Guo et al., out of fifteen patients majority of males were $10(67 \%)$ male and $5(33 \%)$ female patients with an average age of 40 years old. (Guo et al.) ${ }^{[5]}$, whereas in a study, out of 74 DRUJ injury patients majority were female (44) than male (30). Majority $(76 \%)$ of the females were at osteoporotic age (mean 52, range 18-79), while only 5 males had osteoporosis (mean 35, range 18 64). In Pugazhendhi et al. study [6], of 56 DRUJ injury patients $35.7 \%(n=20)$ were males and $64.3 \%(n=36)$ were females $(M: F$ ratio 5:9). The patients distribution was dissimilar in all age distribution groups with the majority $42.9 \%(n=24)$ in the 66 to 75 age group, of 24 patients 16 were female and 8 were male followed next at $32.1 \%(n=18)$ in the age group 56 to 65 years and least $25 \%(\mathrm{n}=14)$ in the age group 46 to 55 years. (Pugazhendhi et al. $)^{[6]}$.

In our study, DRUJ injuries were seen more in left hand (55\%) 
than right $(45 \%)$ hand of patients. Similarly Louis Catalano et al. results found increased involvement of the left wrist than the right wrist. (Louis Catalano et al.) ${ }^{[7]}$, right side (dominant wrist) was more involved $(80 \%)$ than left side with $20 \%$ of the cases which was contradictory to our results. More common right side involvement may be because of more number of right handed persons using their right hand first for protecting themselves while fall on the ground. Pesola et al. ${ }^{[8]}$ suggests a lateralizing predisposition for left distal radius fractures in older compared with younger individuals who are right hand handed. Study results had equal involvement of both wrists. (Bradway JK et al.) ${ }^{[9]}$.

In current study fall on out stretched hand (58\%) is the major mechanism of DRUJ injuries followed by Trivial trauma in $42 \%$.Similarly, in the study of Louis Catalano et al. and majority of patients $67 \%$ fall on out stretched hand followed by study's RTA trauma predisposition is $10 \%$. (Louis Catalano et al.) Bradway JK et al. ${ }^{[9]}$ also reported fall on the outstretched hand as the most common mode of injury contrary to our findings. However, mode of injury in majority of cases was road traffic accident (RTA). Of 20 cases, injury occurred due to road traffic accident in $14(70 \%)$ patients and fall on the out stretched hand in $6(30 \%)$ patients. RTA are more common in the Indian subcontinent may be due to disobeying traffic rules, road conditions, vehicle's condition, driving under influence of alcohol, fast careless driving, inflation and increase in number of vehicles, increased per capital income.

In current study DRUJ injury was missed in $18.33 \%$, chronic in $20 \%$, acute in $38.33 \%$ and sub-acute in $23.33 \%$. Similarly in the study, 83 patients with a total of 93 acute DRF were included in their study. The incidence of DRUJ instability was $22.9 \%$ $(n=17 / 74)$, and majority $(83.33 \%, n=15 / 18)$ of the patients were males. There were three open DRF that were associated with DRUJ instability. Acute DRUJ instability associated with a forearm fracture is more frequent than previously assumed. In a review of forearm injuries, Goldberg et al. reported that two or more sites of injury are routine and that the DRUJ is affected in $60 \%$ of patients. (Goldberg et al.) ${ }^{[10]}$ Complex distal radial fractures may be associated directly with TFCC injury or may render the DRUJ unstable because of an associated fracture of the sigmoid notch, as described by Bowers. Galeazzi fracturedislocations and their variants may be associated with either palmar or dorsal dislocation. Longitudinal instability may accompany radial-head fractures and disruption of the central portion of the interosseous membrane ${ }^{[11]}$. (Bowers) In the study of Squires et al., distal radioulnar joint (DRUJ) plays a key role in forearm stabilization and rotation. It is a site of both acute and chronic injuries and is frequently imaged to evaluate chronic wrist pain, forearm dysfunction, and traumatic forearm injury. (Squires et al.) In the study of Tsai et al., the incidence of DRUJ instability was reported to be 10-19\% after distal radius fracture. (Tsai et al. ${ }^{[12]}$.

\section{Conclusion}

Present study conclude that DRUJ injuries are more prevalent among young males than females. DRUJ injuries was seen more in left $(55 \%)$ than right $(45 \%)$ hand with fall on out stretched hand is the major mechanism. Physical examination is effective in diagnosis; radiological examination suggested for further investigations. Positive symptoms of DRUJ injuries were in $100 \%$, physical examination was positive in $85 \%$ and negative in $15 \%$. Positive CT findings in $66.67 \%$ and negative in $33.33 \%$. $\mathrm{X}$-ray findings were positive in $71.67 \%$ and negative in $28.33 \%$.

\section{References}

1. Louis DS, Jebson PJ. The evolution of the distal radio-ulnar joint. Hand Clin 1998;14:155-9.

2. Niraj Ranjeet, Krishna Sapkota, Pratyenta Raj Onta, Pabin Thapa, Krishna Wahegoankar, Upendra Jung Thapa. Factors associated with Distal Radio-Ulnar Joint (DRUJ) instability in patients with Distal Radius Fractures. Asian Journal of Medical Sciences 2018, 9(5).

3. Geissler WB, Fernandez DL, Lamey DM. Distal radioulnar joint injuries associated with fractures of the distal radius. Clin Orthop Relat Res 1996;327:135-146.

4. May MM, Lawton JN, Blazar PE. Ulnar styloid fractures associated with distal radius fractures: incidence and implications for distal radioulnar joint instability $\mathrm{J}$ Hand Surg (Am) 2002;27(6):965-971.

5. Guo Z, Wang Y, Zhang Y. Modified Sauve-Kapandji Procedure for Patients with Old Fractures of the Distal Radius. Open Med (Wars) 2017;12:417-423. Published 2017 Dec 5.

6. Pugazhendhi G, Srinivasan N, Venkatachalam K. A short term prospective study of the functional outcome of comminuted displaced intra-articular fracture of the distal radius treated with volar locking compression plate. IJOS 2018;4(4):515-519.

7. Catalano LW III, Cole RJ, Gelberman RH, Evanoff BA, Gilula LA, Borrelli J Jr. displaced intra-articular fractures of the distal aspect of the radius. J Bone Joint Surg 1997;79A(9):1290-1302.

8. Pesola GR, Feinberg GA, Ahsan H. Preferential distal radius fracture in right-handed individuals presenting to an ED. Am J Emerg Med 2003;21:552-555.

9. Bradway JK, Amadio PC, Cooney WP. III. Open reduction and internal fixation of displaced, Comminuted intraarticular fractures of the distal end of the radius. $J$ Bone Joint Surg 1989;71-A(6):839-847.

10. Goldberg HD, Young JW, Reiner BI et al. Double injuries of the forearm: A common occurrence. Radiology 1992;185:223-227.

11. Squires JH, Eric England, Kaushal Mehtaand, Robert D. Wissman. The Role of Imaging in Diagnosing Diseases of the Distal Radioulnar Joint, Triangular Fibrocartilage Complex, and Distal Ulna. American Journal of Roentgenology 2014;203:146-153. 10.2214/AJR.13.11573.

12. P.C. Tsai, N. Paksima The distal radioulnar joint Bull NYU Hosp Jt Dis 2009;67(1):90-96. 